\author{
Departamento de Ciência e \\ Tecnologia, Secretaria de \\ Ciência, Tecnologia e Insumos \\ Estratégicos, Ministério da \\ Saúde
}

Correspondência | Correspondence:

Decit - Departamento de Ciência e Tecnologia do Ministério da Saúde

Esplanada dos Ministérios

Bloco G sala 845

70058-900 Brasília, DF, Brasil

Texto de difusão técnico-científica do Ministério de Saúde.

\section{Pontes e obstáculos à apropriação de resultados de estudos e pesquisas para a gestão do SUS}

\section{Obstacles and bypasses for the appropriation of study and research results in SUS management}

Historicamente no Brasil, a incorporação acritíca de tecnologias ${ }^{a}$ vem sendo responsabilizada pelo aumento crescente dos custos setoriais em saúde. Esse diagnóstico aparece relacionado às mais diversas situações, referindo-se desde a aquisição de equipamentos e a utilização de novos medicamentos à implementação de práticas e programas inadequados, quando consideradas as características institucionais, demográficas e epidemiológicas prevalentes. Nesse contexto, é essencial identificar os obstáculos à utilização do conhecimento científico como suporte ao processo de decisão dos gestores, bem como as oportunidades e instrumentos disponíveis para superá-los.

De acordo com os dados do Diretório de Grupos de Pesquisa do Conselho Nacional de Desenvolvimento Científico e Tecnológico - CNPq, "a pesquisa em saúde representa cerca de $30 \%$ da produção científica nacional e conta com mais de 24 mil doutores em ciências da saúde e ciências biológicas". ${ }^{\mathrm{b}} \mathrm{O}$ problema não parece estar, assim, na existência de pesquisadores, embora sua distribuição seja muito heterogênea no território nacional. A concentração de pesquisadores é acentuadamente maior nas regiões Sudeste e Nordeste, e a carência desses profissionais pode ser observada em alguns estados da região Norte e Centro-Oeste.

Nos últimos anos, um número crescente de artigos, produzidos por estudiosos deste tema em muitos países, vem focando o problema na interação entre gestores e pesquisadores. Alguns dos obstáculos são comuns, inclusive aqueles que parecem ter maior identidade com o que pode ser observado no Brasil.
Provavelmente, os obstáculos mais relevantes são relacionados às características do processo de tomada de decisão dos gestores e às dificuldades dos acadêmicos para entendê-las. Entre outros, Gurgel ${ }^{c}$ aponta como elementos importantes desse processo, no Brasil:

- o fato de envolver negociação e busca de consensos entre atores de diferentes níveis hierárquicos, setores, instituições;

- a rotatividade na ocupação de cargos nos órgãos gestores, com solução de continuidade de políticas e programas;

- a predominância de problemas que exigem respostas rápidas, imediatas;

- a agilidade na mudança de temas prioritários e / ou de suas abordagens;

- o papel desempenhado pela ideologia políticopartidária e pela ideologia setorial na tomada de decisão;

- a valorização de experiências e informações diretas em detrimento de estudos e pesquisas.

Ainda segundo essa autora, para que as pesquisas tenham melhores chances de influírem na gestão, elas devem ter uma ou mais das características: estar voltadas para necessidades políticas; atuar na identificação ou no registro da dimensão de problemas; visar ao desenvolvimento de novas idéias ou soluções que expandam o leque de opções possíveis de ação; construir

\footnotetext{
De acordo com a Portaria GM/MS n. 2.510 de 19 de dezembro de 2005, que instituiu a Comissão para Elaboração da Política de Gestão Tecnológica (CPG) no âmbito do Sistema Único de Saúde, o termo "tecnologias" deve ser entendido como compreendendo "medicamentos, materiais e procedimentos, sistemas organizacionais, informacionais, educacionais e de suporte, e os programas e protocolos assistenciais, por meio dos quais a atenção e os cuidados de saúde são prestados".

${ }^{b}$ Conselho Nacional de Secretários de Saúde. Ciência e Tecnologia em Saúde, 2007. Brasília; 2007 (Coleção Progestores - Para entender a gestão do SUS, 4). Disponível em: http://bvsms.saude.gov.br/bvs/publicacoes/colec_progestores_livro4.pdf

${ }^{c}$ Gurgel IGD. A pesquisa científica na condução das políticas de controle de doenças transmitidas por vetores [tese de doutorado]. Recife: Instituto Ageu Magalhães da Fiocruz; 2007.
} 
evidências acerca da efetividade das diferentes intervenções políticas; registrar impactos de intervenções sobre a saúde ou sobre as pessoas, sua capacidade de execução e custos; e, principalmente, apresentar seus resultados em formato que possa ser compreendido por gestores e técnicos.

Uma publicação recente do Departamento de Ciência e Tecnologia (DECIT)/Secretaria de Ciência e Tecnologia e Insumos Estratégicos (SCTIE)/Ministério da Saúde (MS) - "Construindo Pontes entre a Academia e a Gestão da Saúde Pública" - mostra que alguns passos vêm sendo dados para a facilitação desse diálogo por meio da promoção da convergência de agendas de gestão e pesquisa, com a utilização de editais centralizados e descentralizados que permitem aos gestores a explicitação de suas demandas e a identificação de parceiros capazes de atendê-las. Embora o exercício de formulação do problema por parte do gestor e o de sua compreensão e atendimento por parte dos estudiosos sejam ainda incipientes, desde já alguns avanços podem ser identificados. Nessa publicação, são abordadas algumas das prioridades definidas pelos gestores no Pacto pela Vida ${ }^{a}$ e a presença desses temas nos projetos apoiados pela SCTIE no último quadriênio, sendo observada uma correlação expressiva.

Além dos obstáculos citados anteriormente, outros, mais identificados com a realidade brasileira, devem também ser considerados. Entre eles destacam-se os relativos ao acesso dos gestores à informação e a algumas características das organizações. No primeiro caso, incluem-se o perfil de escolaridade dos gestores e a diversidade de sua formação profissional, além das dificuldades para utilização de microcomputadores e de acesso à Internet. No segundo, uma estrutura de tomada de decisão descentralizada e uma burocracia muitas vezes resistente a inovações, o que provoca demoras em sua apropriação pelo setor.

Ao lado das diferenças esperadas entre pessoas que optam por se dedicar a atividades acadêmicas e aquelas que atuam na execução de ações e serviços, outros fatores contribuem para as dificuldades de comunicação entre elas no Brasil, particularmente no que se refere à forma e conteúdo das colocações. Há poucas informações relacionadas ao perfil profissional dos técnicos das secretarias de saúde. De acordo com pesquisa realizada por Fleury et $\mathrm{al}^{\mathrm{b}}$ (1997) sobre o perfil dos secretários municipais de saúde, aproximadamente $30 \%$ deles não tinham o curso superior completo e em torno de $35 \%$ não eram originários da área de saúde. A julgar por pesquisas estaduais realizadas em anos posteriores, ${ }^{c}$ esse quadro não vem apresentando mudanças substanciais. Esses percentuais são maiores nos extratos de municípios menos populosos.

Por sua vez, as dificuldades relacionadas ao acesso à Internet e à utilização de microcomputadores se refletem diretamente como dificuldades de acesso ao conhecimento. Segundo publicação recente do Ministério da Educação e parceiros, ${ }^{\mathrm{d}}$ com base na Pesquisa Nacional por Amostra de Domicílio (PNAD) do Instituto Brasileiro de Geografia e Estatística (IBGE), o uso de Internet e computadores aumentou entre $2001 \mathrm{e}$ 2005, 62,9\% e 48,4\%, respectivamente. Apesar disso, profundas desigualdades regionais foram observadas:

“em um extremo, o Norte e o Nordeste, com
7,9 e 7,6\% de sua população com posse de
computador no domicílio e 4,3 e 5,2\% de sua
população conectada à Internet. Em outro
extremo, as regiões Sudeste e Sul, com 25,8 e
$24,1 \%$ de micros domiciliares e 19,5 e 17,6\%
de disponibilidade de Internet na moradia. As
unidades federadas apresentam situações mais
extremas ainda, que vão desde o Maranhão,
com 3,6\% pessoas com computador e 1,7\% de
Internet nos domicílios, até o Distrito Federal,
com 37,2\% com computador e 29\% com acesso
à Internet no domicílio.”

O próprio potencial de crescimento da utilização da Internet é limitado, quando avaliado sob a luz de um levantamento realizado pelo Ministério das Comunicações. Em 2006, ' havia menos de 700 municípios no Brasil com infra-estrutura de transmissão de dados de alta capacidade, concentrados nas regiões Sul e Sudeste.

\footnotetext{
a A redução da mortalidade infantil e materna, o controle das doenças emergentes e endemias, como a dengue e a hanseníase, e a redução das vítimas de câncer de colo de útero e de mama, além da implementação da Política Nacional de Saúde do Idoso, à elaboração e implantação de uma Política Nacional de Promoção da Saúde e à consolidação da Atenção Básica à Saúde tendo como prioridade o Programa Saúde da Família (PSF).

b Fleury S, Carvalho AI, Manotas N, Bloch R, Nevares S. Municipalização da saúde e poder local no Brasil. Rev Adm Publica. 1997;31(5). Disponível em: http://www.ebape.fgv.br/academico/pdf/municipalizacao_saude_21_enanpad.pdf

c Souza AACL. O Perfil dos secretários municipais de saúde em Minas Gerais e a organização dos programas e projetos municipais. Rev Min Saude Publica. 2002;1(1). Disponível em: http://www.esp.mg.gov.br/comunicacao/imagens_comunicacao/revista/4\%20-\%20O\%20perfil\%2 0dos\%20Secretarios\%20Municipais\%20de\%20Saude.pdf. Vilar RLA. O estudo sobre o perfil dos gestores municipais de saúde do estado do Rio Grande do Norte. Natal: Núcleo de Estudos de Saúde Coletiva da Universidade Federal do Rio Grande do Norte; 2001. Pinto Sobrinho LC, Moura F. Rodrigues FM. Identificação do perfil profissional dos responsáveis pela saúde nos municípios do Rio Grande do Sul. In: Rede Observatório RH da Escola de Saúde Pública. Perfil profissional e a formação em saúde no Rio Grande do Sul. Porto Alegre; 2006 . Disponível em: http://www.esp.rs.gov.br/observatoriorh/img2/projpinto.pdf

d Waiselfise JJ. Lápis, Borracha e Teclado: tecnologia da informação na educação - Brasil e América Latina. Rede de Informação Tecnológica Latino-americana. Brasília: Ritla / Instituto Sangari / Ministério da Educação; 2007. Disponível em:

http://www.ritla.net/index.php?option=com_docman\&task=doc_download\&gid=83

e Conselho Nacional de Secretários de Saúde. Ciência e Tecnologia em Saúde, 2007. Brasília; 2007 (Coleção Progestores - Para entender a gestão do SUS, 4). Disponível em: http://bvsms.saude.gov.br/bvs/publicacoes/colec_progestores_livro4.pdf
} 
No que se refere à incorporação de inovações pelas secretarias de saúde, genericamente referidas como "organizações" anteriormente, poucas são as informações disponíveis. É lícito supor, no entanto, que isso aconteça de forma também heterogênea entre as unidades da federação, considerado o arranjo institucional definido pelas diretrizes do Sistema Único de Saúde (SUS), envolvendo a descentralização do processo decisório. De fato, isso pode ser observado nos resultados das auto-avaliações de nove secretarias estaduais de saúde (SES), com a utilização do instrumento denominado Funções Essenciais de Saúde Pública (FESP), proposto pela Organização Pan-Americana de Saúde (OPAS) e adaptado para a gestão estadual do SUS pelo Conselho Nacional de Secretários de Saúde (CONASS). ${ }^{a}$ Nesse instrumento, a décima função, ou FESP SUS 10, se relaciona à Pesquisa e Incorporação Tecnológica em Saúde e, nela, três indicadores são avaliados:

- desenvolvimento de uma Agenda Estadual de Pesquisa em Saúde;

- desenvolvimento da capacidade institucional de pesquisa e incorporação tecnológica; e

- cooperação e apoio aos municípios, diretamente ou em parceria com instituições acadêmicas, para o desenvolvimento de pesquisas em saúde.

Numa faixa de 0 a 1 , a média das nove SES para essa função foi de 0,51 , com variação de 0,35 a 0,80 , enquanto a da similar da OPS, para 41 países da América
Latina e Caribe, foi de 0,55. Ainda, seis das nove SES, ou $66,7 \%$, se avaliaram abaixo da média.

Com base em todas essas informações, a SCTIE/MS vem trabalhando em diversas frentes com vistas a facilitar o acesso do gestor ao conhecimento científico e a favorecer sua interação com pesquisadores. Entre as estratégias propostas, muitas já implementadas ou em processo de implementação, podem ser citadas: a utilização de diferentes mídias para disseminação (Internet, rádio, TV, publicações); publicações de diferentes naturezas (livros, revista temática, boletins, artigos em revistas de ampla circulação); premiação e divulgação de teses de mestrado, doutorado, especialização e trabalhos publicados; apoio a eventos técnicos e científicos de naturezas diversas; construção de Portal do DECIT, em parceria com a Biblioteca Virtual em Saúde (BVS/BIREME); seminários temáticos nacionais e regionais com a participação de pesquisadores, divulgadores, gestores; promoção de capacitação em divulgação científica.

Trata-se na verdade de disponibilizar novos instrumentos e espaços que possam conectar processos que, de outra forma, ocorreriam de forma independente, propiciando "momentos de oportunidade". Como ensina Báscolo, "momentos de oportunidade" se prestam "para que os atores de um dos processos (investigação ou gestão) possam aprender de ou contribuir para os do outro. O principal desafio de utilizar a investigação para as políticas consiste em aprender a criar ou reconhecer esses momentos e atuar eficientemente para tirar vantagem deles."

\footnotetext{
a Conselho Nacional de Secretários de Saúde. A gestão da saúde nos estados: avaliação e fortalecimento das funções essenciais. Brasília; 2007. Disponível em: http://www.conass.org.br/admin/arquivos/livro_fesp_final_completo

b Ernesto Pablo Báscolo, citando Trostle, Bronfman y Langer, em sua apresentação "Utilización de los resultados de la investigación en el proceso de decisión, formulación e implementación de políticas: una revisión de la literatura", no I Congreso Nacional de Investigación en Salud Pública, Bogotá / Colômbia, em 25 de outubro de 2006.
} 